\title{
ANALISIS LAPORAN KEUANGAN DI ERA DIGITAL
}

\author{
Analysis of Financial Statements in The Digital Era \\ Devica Pratiwi
}

Akuntansi/Fakultas IImu Sosial dan Humaniora, Universitas Bunda Mulia

Diterima 4 Februari 2021 / Disetujui 25 Februari 2021

\begin{abstract}
The rapid development of technology and increasingly high business competition poses a challenge for business people to always be quick and responsive to changes in order to decide on effective strategies to survive in the increasingly tight business world of the industrial world. In the world of accounting, a growing issue of the role of accountants will be replaced by technology. There was a shift in the function of the accountant from working manually to digitization in preparing financial reports and analysis based on the financial information generated. This service activity was carried out on March 16, 2020 in the computer lab room of Bunda Mulia University which consisted of Atisa Dipamkara Tangerang Vocational School students. The event took place from 09.00 - 11.00 starting with the introduction of accounting software, namely Accurate, the available tools and how to operate Accurate to produce financial reports quickly and accurately. Then the explanation is continued by reading the results of the financial statements to determine the merits of the company's performance in a certain period. The results of this activity can be seen from the enthusiasm of the participants with a discussion of questions and answers regarding accounting software and its comparison with the software they have studied at school, then asking about what financial information can be generated from the software and how to prepare accounting information to read the results in easy to understand. The implication of this service activity is that it can provide awareness for participants to be skilled in using technology in preparing financial information and developing soft skills as prospective accountants in communicating this information to interested parties.

Keywords: Accurate, Accounting, Accountant, Financial Report
\end{abstract}

\begin{abstract}
ABSTRAK
Perkembangan teknologi yang pesat dan persaingan bisnis yang semakin tinggi, menjadi tantangan bagi para pebisnis untuk selalu cepat dan tanggap menghadapi perubahan untuk memutuskan strategi-strategi yang efektif untuk tetap bertahan di dunia usaha dunia industri yang yang semakin ketat. Dalam dunia akuntansi, berkembaang issue peran akuntan akan tergantikan oleh teknologi. Terjadi pergeseran fungsi akuntan yang semula bekerja secara manual menuju digitalisasi dalam penyiapan laporan keuangan dan analisis berdasarkan informasi keuangan yang dihasilkan. Kegiatan pengabdian ini dilaksanakan pada 16 Maret 2020 di ruang lab komputer Universitas Bunda Mulia yang terdiri dari siswa-siswi SMK Atisa Dipamkara Tangerang. Acara berlangsung pk 09.00 - 11.00 dimulai dengan perkenalan software akuntansi yaitu Accurate, tools yang tersedia dan bagaimana cara pengoperasian Accurate hingga menghasilkan laporan keuangan dengan cepat dan akurat. Kemudian penjelasan dilanjutkan dengan cara membaca hasil laporan keuangan untuk menentukan baik buruknya kinerja perusahaan pada periode tertentu. Hasil dari kegiatan ini terlihat dari antusias para peserta dengan diskusi tanya jawab terkait software akuntansi dan perbandingannya dengan software yang pernah mereka pelajari di sekolah, kemudian bertanya seputar informasi keuangan apa saja yang dapat dihasilkan dari software dan bagaimana cara menyiapkan informasi akuntansi tersebut hingga cara membaca hasil yang mudah dipahami. Harapan dari kegiatan pengabdian ini adalah dapat memberikan kesadaran bagi peserta untuk terampil dalam pemanfaatan teknologi dalam menyiapkan informasi keuangan dan pengembangan soft skill sebagai calon akuntan dalam mengkomunikasikan informasi tersebut kepada pihak yang bekepentingan.
\end{abstract}

Kata kunci: Accurate, Akuntansi, akuntan, laporan keuangan

Korespondensi Penulis:

dpratiwi@bundamulia.ac.id 


\section{PENDAHULUAN}

\section{Latar Belakang}

Perkembangan teknologi yang pesat dan persaingan bisnis yang semakin tinggi, menjadi tantangan bagi para pebisnis untuk selalu cepat dan tanggap menghadapi perubahan untuk memutuskan strategistrategi yang efektif untuk tetap bertahan di dunia usaha dunia industri yang yang semakin ketat. Dalam dunia akuntansi, berkembaang issue peran akuntan akan tergantikan oleh teknologi. Terjadi pergeseran peran akuntan yang semula bekerja secara manual dalam menyiapkan laporan keuangan menuju kefasihan dalam memanfaatkan teknologi dalam menyiapkan laporan akuntansi dan peran dalam pengambilan keputusan maupun yang bersifat konsultatif.

Berdasarkan informasi dari Menteri

Riset, Teknologi dan Pendidikan Tinggi (Menristekdikti) Mohamad Nasir (2018), Revolusi Industri 4.0 terjadi pergeseran yang luar biasa pada berbagai bidang ilmu dan profesi, oleh karena itu cara kerja dan praktik akuntan perlu diubah untuk meningkatkan kualitas layanan dan ekspansi global melalui komunikasi daring dan penggunaan cloud computing. Menristekdikti berpesan agar para akuntan di era digital tidak boleh memandang sebelah mata dampak dari teknologi, dan perlu menguasai data non-keuangan seperti data analysis, information technology development, dan leadership skills.

$$
\text { Dilanjutkan informasi dari }
$$

organisasi akuntan dunia (International Federation of Accountants/ IFAC) melalui Ikatan Akuntan Indonesia (IAI) pada Prakarsa 6.1. Tahun 2019, yang menyebutkan jika profesi akuntansi di seluruh dunia akan menghadapi perubahan signifikan dalam tiga dekade mendatang. Beberapa perubahan yang harus segera direspon organisasi profesi, anggota, dan stakeholders-nya adalah teknologi digital yang terus berkembang, globalisasi atas standar pelaporan, dan perubahan regulasi. Penggunaan teknologi pintar hampir di seluruh bidang pendukung kehidupan telah merevolusi cara kerja tradisional akuntan dan ini merupakan suatu tantangan besar bagi profesi akuntan.
Kemudian berdasarkan penelitian yang dilakukan oleh Iswanto dan Wahjono (2019), ada empat langkah yang harus diambil akuntan didalam menghadapi revolusi industri 4.0 yang dikutip dari International Edition of Accounting and Business Magazine edisi Desember 2016, Roger Leonard Burrit dan Katherine Christ, yaitu Kesadaran (Awareness) bahwa dengan revolusi industri melahirkan peluang atau kesempatan baru, pendidikan (education), regulator atau pemerintah dan praktisi pendidikan dituntut untuk dapat membuat kurikulum yang relevan disesuaikan dengan perkembangan konektifitas digital, pengembangan profesi (professional development), dan penerapan standar tinggi (Reaching out). Empat langkah di atas dapat dimulai pada awal proses Pendidikan agar dapat mempersiapkan calon-calon lulusan akuntan yang kompeten dan sesuai dengan keinginan pasar karena disesuaikan dengan kebutuhan nyata di dunia bisnis saat ini.

Berdasarkan informasi-informasi di atas, Program Studi Akuntansi Universitas Bunda Mulia menyelenggarakan kegiatan Pengabdian kepada Masyarakat dengan tema analisis laporan keuangan di Era Digital untuk mengenalkan software akuntansi yaitu Accurate, tools yang tersedia dan bagaimana cara pengoperasian Accurate hingga menghasilkan laporan keuangan dengan cepat dan akurat. Kemudian penjelasan dilanjutkan dengan cara membaca hasil laporan keuangan untuk menentukan baik buruknya kinerja perusahaan pada periode tertentu. Target pesertanya adalah siswa-siswi SMK Atisa Dipamkara, Tangerang.

Accurate dipilih sebagai software akuntansi yang digunakan dalam kegiatan pengabdian ini karena software ini digunakan hampir diseluruh bidang usaha, seperti usaha jasa, usaha dagang, usaha kontraktor hingga usaha manufaktur. Berdasarkan data dari website www.cpssoft.com, lebih dari 150.000 perusahaan dan Lembaga di Indonesia telah menggunakan Accurate. 


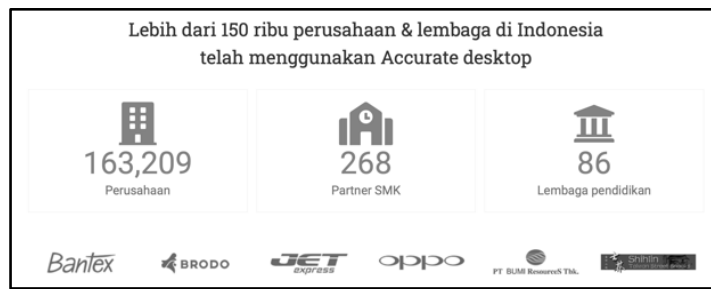

Gambar 1. Data Penggunaan Accurate di Indonesia

Sumber: https://cpssoft.com/accurate/

Sehingga dengan perkembangan teknologi saat ini dan tuntutan profesi akuntan yang harus fasih dalam pemanfaatan teknologi, pembelajaran kepada peserta pada kegiatan pengabdian masyarakat sudah tepat menggunakan software akuntansi yang cukup banyak telah digunakan pada lembaga dan perusahaan yang tersebar di Indonesia.

\section{Identifikasi Masalah}

Pergeseran peran dan fungsi akuntan yang semula pekerjaan diselesaikan secara manual dan berfokus pada penyusunan laporan keuangan, kini dengan berkembangnya teknologi dan ketatnya persaingan bisnis, akuntan dituntut untuk fasih dalam memanfaatkan teknologi dalam penyelesaian laporan akuntansi dan mampu menganalisisnya hingga menjadi sebuah informasi yang dapat digunakan untuk proses pengambilan keputusan yang efektif.

Penggunaan software akuntansi juga sudah berkembang saat ini, salah satunya Accurate yang sudah digunakan lebih dari 150.000 lembaga dan perusahaan di Indonesia, sehingga topik kegiatan pengabdian masyarakat ini cukup penting untuk dibagikan mulai dari siswa-siswi SMK yang berfokus pada jurusan akuntansi, untuk dibekali ilmu akuntansi yang berbasis teknologi dan cara menganalisis laporan keuangan yang dihasilkan.

\section{Tujuan dan Manfaat Kegiatan}

Kegiatan pengabdian kepada masyarakat ini diharapkan dapat memberikan tujuan dan manfaat sebagai berikut:

1. Memperkenalkan software akuntansi dan cara penggunaannya untuk menambah kemampuan peserta dalam menyusun laporan keuangan dengan teknologi.
2. Memberikan pengetahuan dan menambah softskill peserta kegiatan dalam cara membaca hasil laporan keuangan dalam menilai kinerja perusahaan.

3. Memberikan kesadaran kepada peserta kegiatan agar memahami pentingnya menguasai teknologi dalam mendalami profesi akuntan.

\section{METODE PENELITIAN}

Kegiatan pengabdian kepada masyarakat ini memiliki target peserta siswa-siswi SMK Atisa Dipamkara Tangerang kelas XI yang diselenggarakan di ruang lab komputer Akuntansi Universitas Bunda Mulia. Teknik penyampaian informasi dengan metode blended learning, memanfaatkan komputer dengan software akuntansi dan masingmasing peserta juga dibekali dengan perangkat komputer untuk mengikuti proses kegiatan. Berdasarkan Oktarina, dkk (2020), metode blended learning atau pembelajaran tatap muka yang memanfaatkan media komputer (Ekayati, 2018) akan dapat memberikan pengalaman baru terhadap audience dalam memahami materi pembelajaran. Selain itu penyampaian informasi dengan menggunakan komunikasi dua arah juga bermanfaat dalam menimbulkan diskusi aktif terjadi antara peserta dengan narasumber.

Kegiatan dibagi menjadi tiga bagian, yang pertama adalah perkenalan software akuntansi yaitu Accurate dan tools yang tersedia. Peserta akan diperlihatkan menumenu yang tersedia di Accurate pada layar LCD dan komputer masing-masing. Kemudian dilanjutkan dengan praktik oleh peserta kegiatan dalam mengoperasikan software mengikuti arahan narasumber menggunakan komputer masing-masing sehingga materi lebih mudah dipahami dengan praktek langsung oleh peserta. Pada sesi ini diberikan contoh beberapa transaksi lengkap berupa siklus penjualan dan pembelian. Kemudian juga diperkenalkan contoh-contoh transaksi lain dan tahapan apa yang perlu dilakukan pada menu yang tersedia di Accurate. Pada tahap akhir, diajarkan cara menyiapkan laporan keuangan 
yang diambil dari Accurate sekaligus cara membaca laporan keuangan yang dihasilkan. Kegiatan ditutup dengan diskusi tanya jawab seputar pengoperasian Accurate dan Analisis Laporan Keuangan. Kegiatan akan berlangsung kurang lebih selama 120 menit.

\section{HASIL DAN PEMBAHASAN}

Kegiatan dilaksanakan pada 16 Maret 2020 pk 09.00 - 11.00. Peserta sejumlah 16 siswa-siswi kelas XI dari SMK Atisa Dipamkara berkumpul di Ruang Lab Komputer Universitas Bunda Mulia Kampus Serpong. Narasumbernya adalah Devica Pratiwi, S.E., M.Ak. sebagai dosen tetap Prodi Akuntansi. Sesi pertama diawali dengan perkenalan software akuntansi yaitu Accurate dan tools apa saja yang tersedia untuk dijalankan. Pada Accurate tersaji 6 menu pilihan yang dapat terlihat pada gambar 1 , untuk perusahaan yang baru menggunakan accurate dalam kegiatan operasionalnya, dapat memilih Create New Company/ Buat Data Perusahaan Baru (ditunjukkan pada simbol huruf A) untuk membuat database baru. Bila perusahaan sebelumnya sudah membuat database accurate dan bermaksud untuk melanjutkan proses input transaksi, dapat memilih Open Existing Company/Buka Data Perusahaan (ditunjukkan pada simbol huruf B).

Kemudian bila seorang akuntan memiliki beberapa klien perusahaan dan memilih dengan klik Open Last Company/ Buka data Perusahaan Terakhir (ditunjukkan pada simbol huruf C) maka file database yang terbuka adalah klien yang terakhir kali dikerjakan oleh akuntan pada accurate. Menu pilihan Explorer Sample Company Accurate/ Jelajahi Data Perusahaan Contoh (ditunjukkan pada simbol huruf D) adalah menyajikan contoh-contoh database perusahaan yang disediakan oleh Accurate dan perlu terhubung dengan koneksi internet. Bila database mengalami kerusakan atau cacat dapat diperbaiki dengan memilih menu Repair Datal Perbaiki Data (ditunjukkan pada simbol huruf E) atau kita dapat membuka file database cadangan pada menu Restore Datal
Data Cadangan (ditunjukkan pada simbol huruf F).

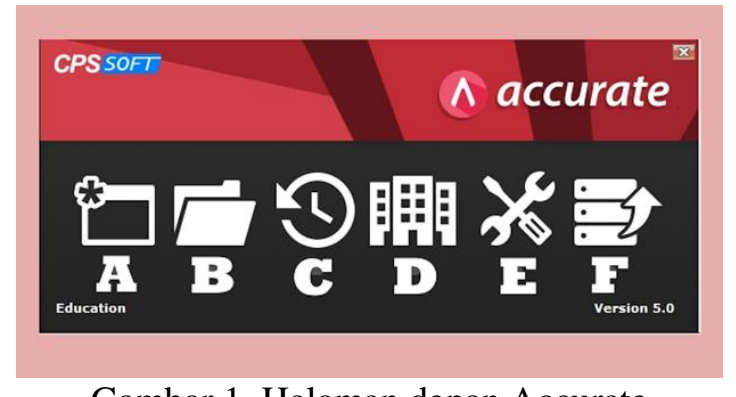

Gambar 1. Halaman depan Accurate

Sumber: Perdiasari (2015) dan Peneliti (2020)

Selanjutnya peserta diajarkan input transaksi ke dalam bukti transaksi untuk proses penyelesaian siklus akuntansi dalam periode tertentu, salah satunya adalah transaksi siklus penjualan dan siklus pembelian. Peserta diperkenalkan formularformulir apa sajaj yang ada pada modul penjualan dan pembelian di Accurate dan bagaimana tahapan input data ke dalam bukti transaksi tersebut.

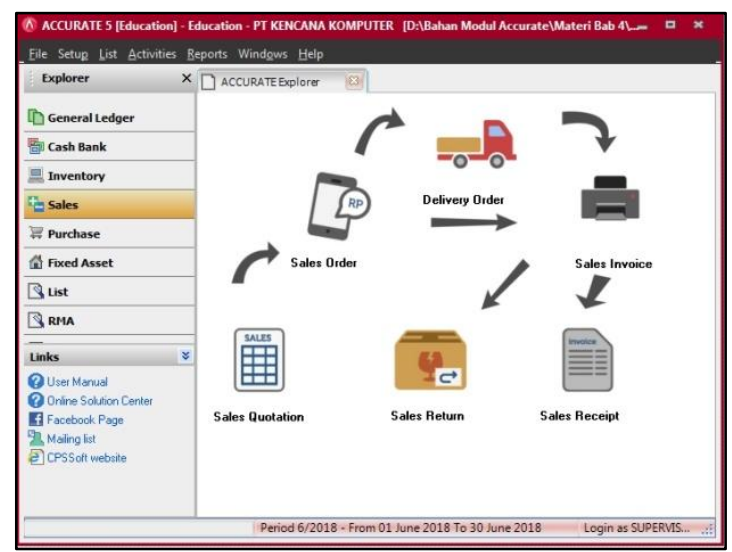

Gambar 2. Siklus Pada Modul Penjualan Sumber: Perdiasari (2015) dan Peneliti (2020)

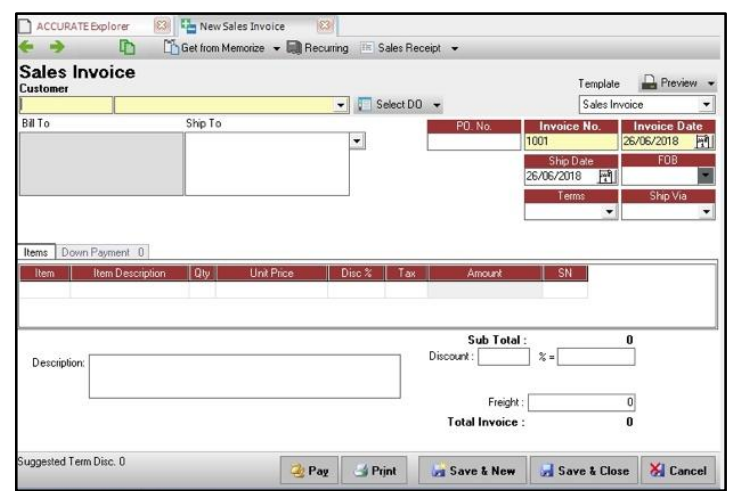


Gambar 3. Faktur Penjualan

Sumber: Perdiasari (2015) dan Peneliti (2020)

Pada modul penjualan seperti pada Gambar 2, peserta diperkenalkan bahwa tahapan-tahapan dalam siklus penjualan dibagi menjadi: sales quotation (penawaran penjualan) adalah form penawaran harga oleh sales perusahaan kepada calon pelanggan. Kemudian bila terjadi pemesanan oleh pelanggan maka akan dibuat form sales order (pesanan penjualan). Barang yang sudah tersedia perlu diantar ke pelanggan dengan menerbitkan form delivery order (pengiriman pesanan) dan bila perusahaan ingin mengirimkan tagihan kepada pelanggan, maka dapat menginput prosesnya pada sales invoice (faktur penjualan).

Ketika terjadi ketidaksesuaian barang, pelanggan dapat mengembalikannya dan perusahaan akan menerbitkan form sales return (retur penjualan). Pada akhirnya, ketika tanggal jatuh tempo pelanggan melunasi piutannya maka perusahaan mencatatnya pada form sales receipt (penerimaan penjualan/ pembayaran dari pelanggan). Suatu transaksi penjualan tunai juga dapat terjadi, maka perusahaan dapat langsung memprosesnya pada form sales invoice dan sales receipt.

Selanjutnya peserta dikenalkan pada modul pembelian. Pada gambar 3, terlihat tahapan-tahapan yang dilalui pada sebuah siklus pembelian. Dimulai dari permintaan dari pihak Gudang dengan mengisi form purchase requisition (permintaan pembelian) dan kemudian akan dilanjutkan prosesnya dengan menerbitkan form purchase order (pesanan pembelian). Kemudian dilanjutkan ketika pesanan diterima perusahaan dari pemasok, maka diinput form receive item (penerimaan pesanan). Ketika pemasok mengirimkan tagihan, maka akan diproses form purchase invoice (faktur pembelian). Pada akhirnya saat melakukan pelunasan kepada pemasok, maka akan diisi form purchase payment (pembayaran pembelian/ pembayaran kepada pemasok). Sama seperti siklus penjualan, bila terjadi pembelian secara tunai, maka form yang dapat diisi adalah purchase invoice dan purchase payment.

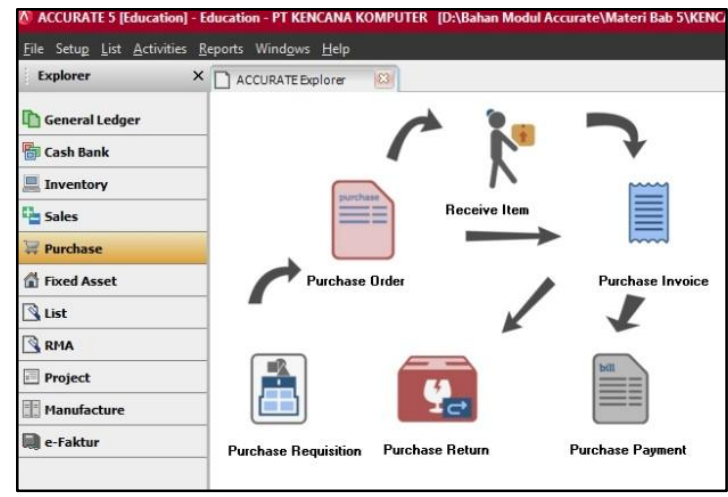

Gambar 4. Siklus Pembelian

Sumber: Perdiasari (2015) dan Peneliti (2020)

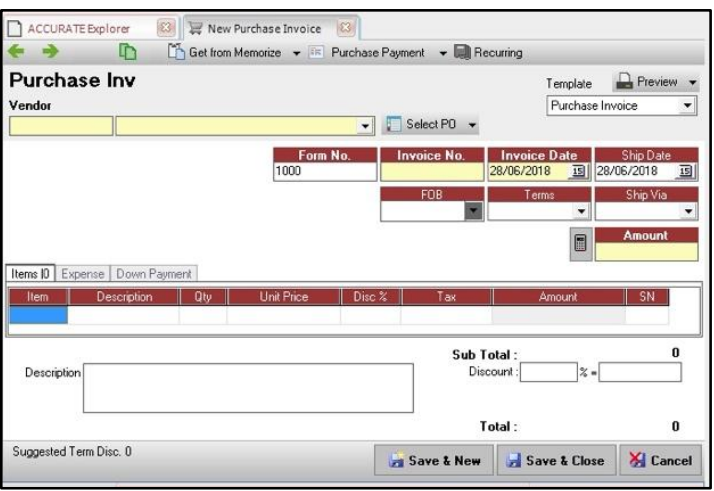

Gambar 5. Faktur Pembelian

Sumber: Perdiasari (2015) dan Peneliti (2020)

Selain siklus penjualan dan pembelian, peserta diperkenalkan modul lain yang tersedia di Accurate. Bila terjadi transaksi penerimaan atau pembayaran di luar penjualan dan pembelian, maka perusahaan dapat input data tersebut pada form deposit (penerimaan lain-lain) atau payment (pembayaran lain-lain), yang terjadi pada gambar berikut ini:

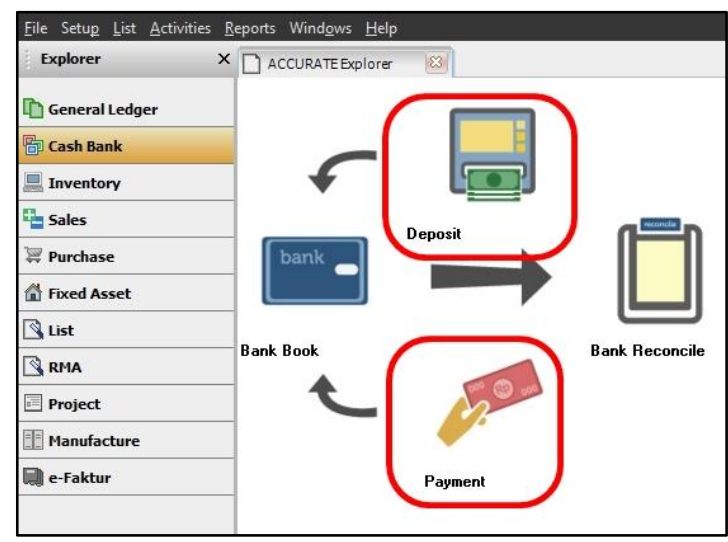

Gambar 6. Deposit dan Payment

Sumber: Perdiasari (2015) dan Peneliti (2020) 
Contoh transaksinya adalah seperti adanya pembayaran biaya administrasi bank, pembayaran gaji karyawan, penerimaan pendapatan bunga dan lainnya.

Bila ada suatu transaksi yang tidak berkaitan dengan penerimaan atau pembayaran, seperti mengakui beban gaji terutang atau membuat jurnal penyesuaian, maka perusahaan dapat menginput form journal voucher (jurnal umum) pada accurate seperti pada gambar 7 .

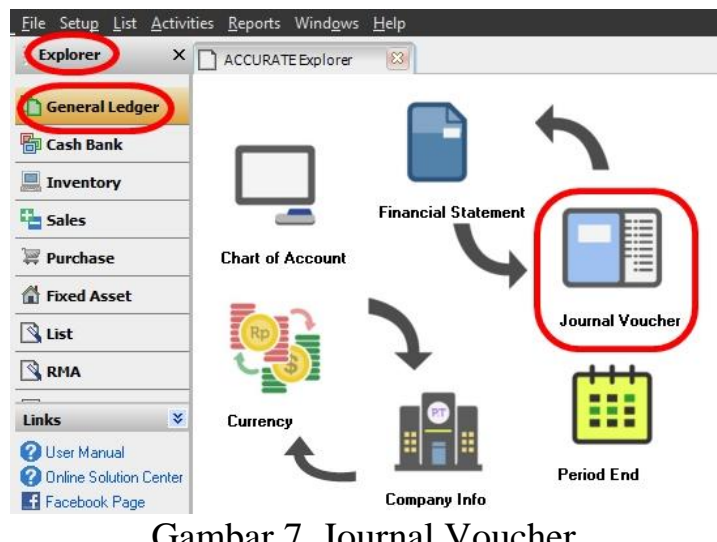

Sumber: Perdiasari (2015) dan Peneliti (2020)

Kemudian bila perusahaan membeli aset tetap baru atau menjual, hingga menghapus aset tetap yang dimiliki, maka digunakan modul Fixed Asset yang tersaji pada gambar 8 berikut ini:

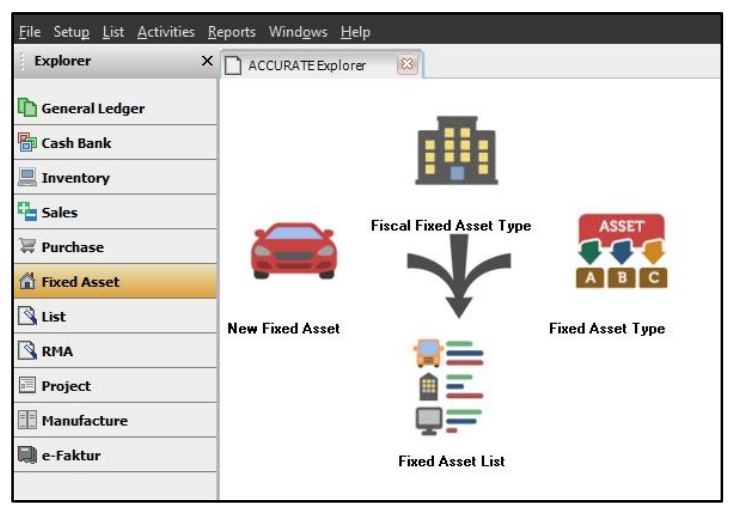

Gambar 8. Modul Aset Tetap

Sumber: Perdiasari (2015) dan Peneliti (2020)

Perusahaan harus melakukan pencatatan tipe aset tetap pajak pada menu Fiscal Fixed Asset Type, kemudian dilanjutkan penyesuaian aset tetap dengan tipe aset tetap pajak pada menu Fixed Asset Type dan baru dapat memasukkan semua aset tetap yang dimiliki perusahaan pada New Fixed Asset untuk mencatat deskripsi aset secara lengkap. Kita dapat melihat daftar aset tetap yang dimiliki pada menu Fixed Asset List dan proses penghapusan atau penjualan aset tetap juga dapat dilakukan melalui menu tersebut.

Tahap terakhir adalah menarik data laporan keuangan dari Accurate dan melakukan analisa dari laporan tersebut. Pada gambar 10 diperlihatkan tampilan laporan apa saja yang tersedia dalam Accurate yang memudahkan penggunanya untuk segera menyajikan laporan akuntansi yang akan digunakan sebagai dasar analisis.

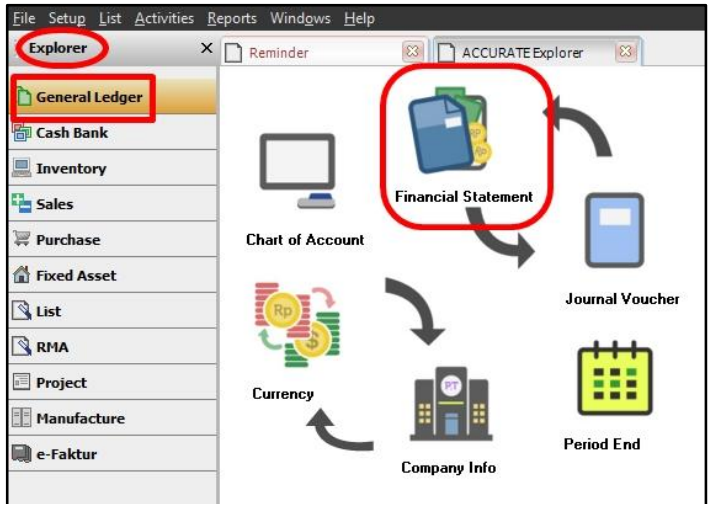

Gambar 9. Menu Laporan Keuangan Sumber: Perdiasari (2015) dan Peneliti (2020)

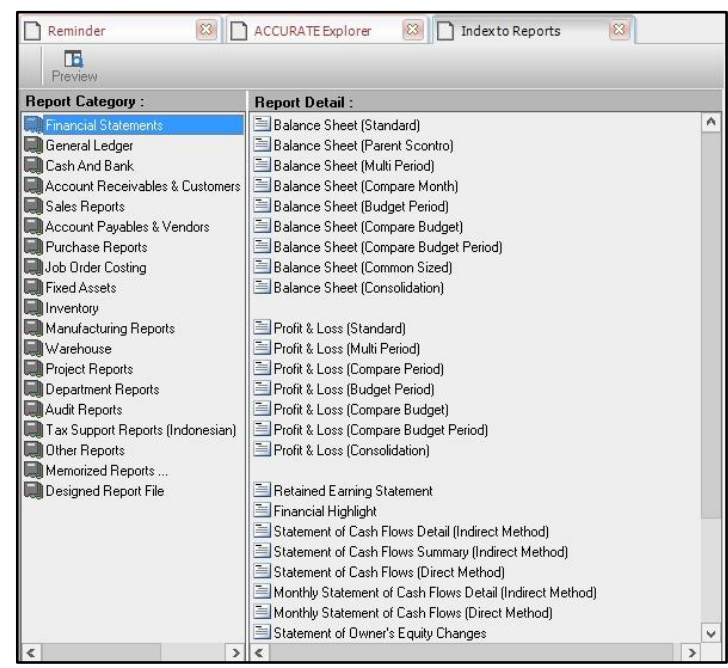

Gambar 10. Daftar Laporan Keuangan yang Tersedia dalam Accurate

Sumber: Perdiasari (2015) dan Peneliti (2020)

Pada tahapan ini laporan yang dicoba untuk dianalisis adalah laporan posisi keuangan dengan menggunakan rasio likuiditas untuk 
mengukur kemampuan jangka pendek perusahaan untuk membayar kewajiban yang jatuh tempo dan untuk memenuhi kebutuhan kas yang tidak terduga (Weygandt, Kimmel, Kieso, 2018). Rasio yang diajarkan dan rumusnya terdiri dari:

Tabel 1. Rasio Likuiditas

\begin{tabular}{|ll|c|}
\hline \multicolumn{1}{|c|}{$\begin{array}{c}\text { Rasio } \\
\text { Likuiditas }\end{array}$} & Rumus \\
\hline 1. & $\begin{array}{l}\text { Current } \\
\text { Ratio }\end{array}$ & $\frac{\text { Current asset }}{\text { Current liabilities }}$ \\
\hline 2. & $\begin{array}{l}\text { Acid-tes } \\
\text { Ratio }\end{array}$ & $\begin{array}{c}\text { Cash }+ \text { short term } \\
\text { investment }+ \text { receivable } \\
\text { (net) }\end{array}$ \\
\cline { 2 - 3 } & $\begin{array}{l}\text { Account } \\
\text { Receivable } \\
\text { Turnover }\end{array}$ & $\frac{\text { Net credit sales }}{\text { Average net A/R }}$ \\
\hline 4. & $\begin{array}{l}\text { Inventory } \\
\text { Turnover }\end{array}$ & $\frac{\text { COGS }}{\text { Average inventory }}$ \\
\hline
\end{tabular}

Sumber: Weygandt, Jerry J., Paul D. Kimmel, Donald E. Kieso. (2018)

Hasil dari penghitungan rasio tersebut kemudian diterjemahkan untuk memudahkan pemahaman peserta terhadap angka yang tercantum pada hasil setiap rasio.

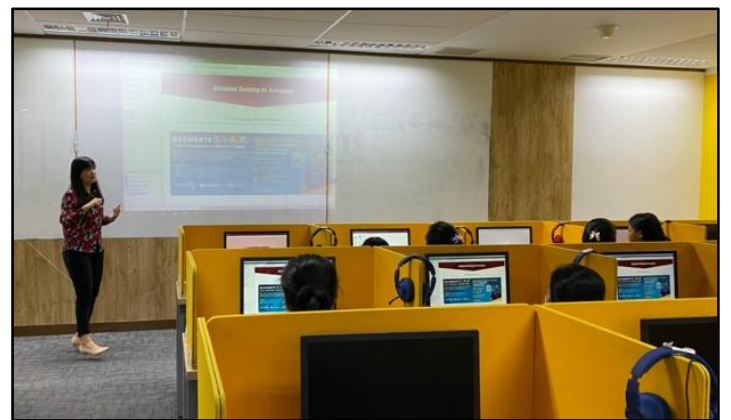

Gambar 11. Pemaparan Analisis Laporan

Keuangan

Sumber: Peneliti (2020)

Selama kegiatan berlangsung, diskusi aktif terjadi antara peserta dan narasumber dalam pembahasan mengenai apa kelebihan dari software akuntansi yang digunakan di UBM dengan yang mereka gunakan di sekolah, bagaimana cara memperbaiki dokumen transaksi yang salah atau membatalkan transaksi yang ter-input dua kali, hingga cara mengkomunikasikan hasil analisis laporan keuangan kepada pihak berkepentingan menggunakan bahasa yang mudah dipahami, terutama untuk pengguna laporan yang tidak memahami akuntansi. Setiap pertanyaan dijawab oleh narasumber dan juga dibantu oleh peserta yang sebelumnya juga pernah berpengalaman dalam menggunakan aplikasi ini.

\section{SIMPULAN}

Kegiatan pengabdian masyarakat dengan topik Analisis Laporan Keuangan di Era Digital secara keseluruhan berlangsung dengan lancar dan diskusi aktif dengan para siswa-siswi SMK Atisa Dipamkara. Dengan terlaksananya kegiatan ini diharapkan semua peserta menyadari bahwa keahlian dalam menyusun laporan keuangan secara manual hanyalah bekal awal mereka untuk mengenal ilmu akuntansi.

Bila ingin sukses berkarir pada profesi akuntan, maka diperlukan penguasaan teknologi dan mengembangkan soft skill khususnya di bidang akuntansi. Hal ini dapat diperoleh pada pembelajaran di Pendidikan tingkat tinggi atau universitas yang menawarkan materi pratikum akuntansi yang berbasis digitalisasi atau melalui ujian sertifikasi yang tersedia di lembaga nasional atau internasional khusus bidang akuntansi.

Beberapa gelar profesi yang dapat diambil seorang akuntan untuk meningkatkan skill dan memberikan value added ketika masuk ke dunia usaha dunia industri Sertifikasi yang dapat ditempuh antara lain: Chartered Accountant (CA), Certified Management Accountant (CMA), Certified Public Accountant (CPA), Certified Practising Accountant (CPA Australia), ICAEW Certified in Finance, Accounting, and Business (ICAEW CFAB) dan Qualified Intenal Auditor (QIA).

Sehingga jangan takut akan peran akuntan yang tergantikan teknologi, karena akuntan kini identik dengan pengambilan keputusan bisnis yang sangat mengerti seluk beluk proses bisnis dan pernak-perniknya. Akuntan kini mampu merambah berbagai 
sektor hingga ke posisi terbaiknya. Akuntan pula yang kini banyak mewarnai kebijakan, bahkan tidak melulu terbatas pada kebijakan bisnis dan ekonomi (IAI, 2015).

\section{DAFTAR PUSTAKA}

Biro Kerjasama dan Komunikasi Publik Kemenristekdikti. (2018, Desember 12). Profesi Akuntan Harus Beradaptasi Dengan Revolusi Industri 4.0. Diakses dari https://www.ristekbrin.go.id/menristekdiktiprofesi-akuntan-harus-beradaptasi-denganrevolusi-industri-4-0/

Ikatan Akuntan Indonesia. (2015, Desember 17). International Seminar: "Ancaman Atau Peluang?". Diakses dari http://www.iaiglobal.or.id/v03/beritakegiatan/detailberita-878=internationalseminar-ancaman-atau-peluang

Ekayati, R. (2018). Implementasi Metode Blended Learning Berbasis Aplikasi Edmodo. Jurnal Teknologi Informasi Dan Ilmu Komputer.

Ikatan Akuntan Indonesia.(2019, Januari 14). Prakarsa 6.1. diakses dari http://www.iaiglobal.or.id/v03/materipublikasi/kategori-24-kit-prakarsa-61

Liliana, Venny (2017). Soal-Soal Kasus Accurate. PT Ultima Tekno Solusindo: Jakarta.

Perdiasari, Lutfia. (2015). Mastering Accurate. Bisnis 2030: Jakarta.

Oktarina, Rahmi, Ambiyar, Fhadillah. (2020). Efektivitas Komunikasi Dua Arah Pada Blended Learning Berorientasi Flipped Classroom Pada Masa New Normal Covid 19. Media Bahasa, Sastra, dan Budaya Wahana, Volume 26, nomor 2, 2020.

Weygandt, Jerry J., Paul D. Kimmel, Donald E. Kieso. (2018). Financial Accounting with International Financial Reporting Standards, 4th Edition. Wiley: New York 